\title{
Modelling the Steady State and Dynamic Conditions of a Biotrickling Filter Treating Styrene and Acetone in Air
}

\author{
Andrew Mark Gerrard ${ }^{1}$, Josef Havranek ${ }^{1,2}$, Vratislav Novak $^{2}$, Martin Halecky ${ }^{2}$, Kim \\ Jones $^{3}$, Carlos Ricardo Soccol ${ }^{4}$ and Jan Paca ${ }^{2 *}$ \\ ${ }^{1}$ University of Teesside; School of Science and Technology; Middlesbrough; TS1 3BA; England. ${ }^{2}$ Institute of \\ Chemical Technology; 16628 Prague - Czech Republic. ${ }^{3}$ South Texas Environmental Institute; Texas AandM \\ University-Kingsville; Kingsville; TX 78363; USA. ${ }^{4}$ Departamento de Engenharia Química; Divisão de Engenharia \\ de Bioprocessos e Biotecnologia; Universidade Federal do Paraná; Curitiba - PR - Brasil
}

\begin{abstract}
The aim of this work was the study a trickling biofilter, where water was circulated throughout the bed. In the first steady state experiment, the packing materials used were $25 \mathrm{~mm}$ Pall rings. The airflow rate was increased gradually and the concentration of styrene in the air stream was held constant. In the second experiment, $15 \mathrm{~mm}$ Pall rings were used. In this case, the feed contained both styrene and a small amount of acetone. The concentration of acetone and the air flow rate were kept constant, but the styrene inlet concentration was increased. The concentrations were measured at the input, and also at an intermediate and the outlet position in the biotrickling filter to determine the concentration profile along the reactor. Using the values of coefficient of determination $\left(R^{2}\right)$ and the coefficient of variation of the fitted constant as criteria, a zero order model with diffusional limitation was chosen as the best representation of the data. Then a further, third, set of experiments were done at unsteady state, using step changes of the inlet concentration levels of both styrene and acetone at a steady air flow-rate. Inlet and outlet concentrations were measured as a function of time and the results were adequately described using a simple first order model.
\end{abstract}

Key words: Biotrickling filter; steady state; unsteady state; mathematical models, styrene, acetone

\section{INTRODUCTION}

Waste gases are often emitted by small chemical factories, refineries, colour, paint and ink manufacturers and chemical product end users (Paca et al., 2007). Treating the exhaust is a very complex process affected by large numbers of factors including biodegradation kinetics, oxygen availability in the biofilm, microbial ecology, spacial distribution of the biofilms, moisture content of the packing material, $\mathrm{pH}$, temperature, and flow characteristics through porous media (Baltzis et al., 1997). Thus, effective modelling of the biotrickling filtration process which could lead to reliable performance equations could reduce the time and cost of experiments at the pilot-stage.

This study was focused on the modelling of styrene (and subsequently acetone) removal in the biotrickling filters (BTF). These compounds can affect human health and welfare. The principal health effects due to styrene exposure involve the central nervous system. Symptoms include

*Author for correspondence: jan.paca@vscht.cz 
subjective complaints of headache, fatigue, dizziness, confusion, drowsiness, malaise, difficulty in concentrating, and a feeling of intoxication. The International Agency for Research on Cancer (IARC) also classifies styrene as a potential human carcinogen. Exposure to moderate-to-high amounts of acetone can irritate eyes and the respiratory system, and cause dizziness; indeed, a very high exposure may cause loss of consciousness.

Biofiltration is a relatively new, alternative way of treating air polluted with volatile organic compounds (VOCs). The polluted gas passes through the carrier materially co- or counter currently to the mobile liquid phase, which ensures an availablenutrient supply to the microorganisms (Kennes and Thalasso, 1998). The VOC's are absorbed and then broken down by the microorganisms into harmless products. Other studies have emphasised the importance of back-washing in the operation of trickling biofilters (Sorial et al., 1998). In some instances, reversing the flow in the biofilter can offer benefits (Wright 2005).

Competing processes include adsorption, scrubbing, condensation and oxidation. Biofiltration processes can be both economic and efficient due to their low operational and capital costs, together with the effective removal of the pollutant, low pressure drop and their ability to treat acid-producing contaminants.

On the other hand, difficulties in controlling $\mathrm{pH}$ and moisture content, large footprint requirements and further production of waste streams can be drawbacks. But in spite of these disadvantages, biofiltration processes are a powerful tool for offgas treatment (Devinny et al., 1999, Choi et al., 2004). An improved understanding of modelling for biofiltration is also needed to enhance the applications and designs for the technology. In this work, a combination of experimental data evaluation and model parameter estimation are used to better describe the biofiltration performance for the removal of a mixture of hydrophobic (styrene) and hydrophilic (acetone) organic pollutants.

\section{MATERIAL AND METHODS}

\section{Design and operating conditions of bioreactors}

A flow sheet of the bench-scale biotrickling filter applied for the steady state experiments is shown in Fig. 1. The reactor consisted of three cylindrical compartments. The two upper sections were made of tempered glass with total height of $150 \mathrm{~cm}$. The third segment, made of polypropylene, served as a sump for circulating liquid. The sump was separated from the column by a perforated plate. All the three sections had an internal diameter of $15 \mathrm{~cm}$. The reactor was packed with polypropylene Pall rings (either $25 \times 25 \times 1 \mathrm{~mm}$ or $15 \times 15 \times 1 \mathrm{~mm})$ up to a bed height of $100 \mathrm{~cm}$. The cylindrical unit and auxiliary appliances [water circulating pump (Micropump, USA), peristaltic pumps, syringe pumps] were placed in a supporting steel structure. The circulating water medium volume was $5 \mathrm{~L}$, and the liquid flowrate was $0.66 \mathrm{~L} / \mathrm{min}$. The medium $\mathrm{pH}$ value was set to $7.0 \pm 0.2$ and this level was maintained by the addition of $0.1 \mathrm{M} \mathrm{NaOH}$ solution. A dose of alkaline solution was supplied to the reactor by a peristaltic pump, which, as the reactor had no air humidifier, also had the effect of replenishing the evaporated water content.

For the first experiment (i) the biotrickling filter was operated in up-flow, counter-current mode for the steady state experiments with only styrene as the pollutant of interest. The loading was performed by increasing the air flow rate from 20 to $80 \mathrm{~L} / \mathrm{min}$ with a constant styrene inlet concentration of $100 \mathrm{mg} / \mathrm{m}^{3}$, giving a range of empty bed residence times of 13.2 to $53 \mathrm{~s}$ (i.e. the organic loading rate from $6.8 \mathrm{~g} / \mathrm{m}^{3} / \mathrm{h}$ to 27.2 $\left.\mathrm{g} / \mathrm{m}^{3} / \mathrm{h}\right)$.

However, the use of $25 \mathrm{~mm}$ Pall rings did not result in acceptable values of removal efficiencies and removal rates (probably because of too large a void volume and too small a specific surface area for biofilm attachment). Hence, smaller polypropylene Pall rings $(15 \times 15 \times 1 \mathrm{~mm})$ in the next set of experiments were used. Furthermore, to elucidate the performance parameters of the biotrickling filter treating a mixture of hydrophobic and hydrophilic components in the vapour phase, a mixture of styrene and acetone was applied in the second experiment. Here, the loading was achieved by increasing the styrene concentration (from 50 to $700 \mathrm{mg} / \mathrm{m}^{3}$ ), and keeping a constant acetone concentration (50 $\mathrm{mg} / \mathrm{m}^{3}$ ) in the inlet air (series ii).

The air flow rate of $20 \mathrm{~L} / \mathrm{min}$ was kept constant. These conditions gave a range of the loading rate from 3.4 to $47.6 \mathrm{~g} / \mathrm{m}^{3} / \mathrm{h}$. As acetone was completely soluble in water, the co-current mode of operation was chosen for the second set of steady state experiments (Fig. 1b). The circulating 
medium volume was $4 \mathrm{~L}$ and the air flow rate remained constant at $20 \mathrm{~L} / \mathrm{min}$. The third (dynamic) set of experiments was also cocurrently operated as the second series, the styrene and acetone levels were stepped up and down as described later. The column temperatures were stable at at $21 \pm 1{ }^{\circ} \mathrm{C}$ (series iii).

Fig 2 shows the schematic for the production of artificially polluted air with a mixture of styrene and acetone.

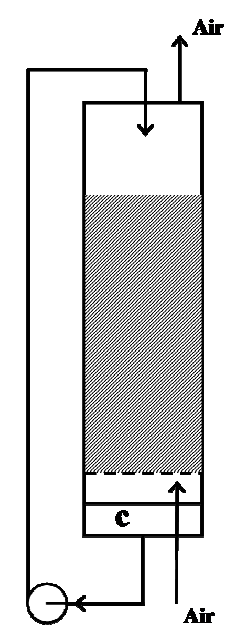

$\mathbf{a}$

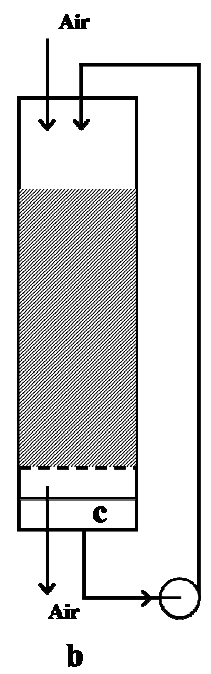

Figure 1 - Flow sheet of the trickle-bed reactor. $\mathrm{a}$ - counter-current operation, $\mathrm{b}$ - co-current operation, $\mathrm{c}$ - water medium

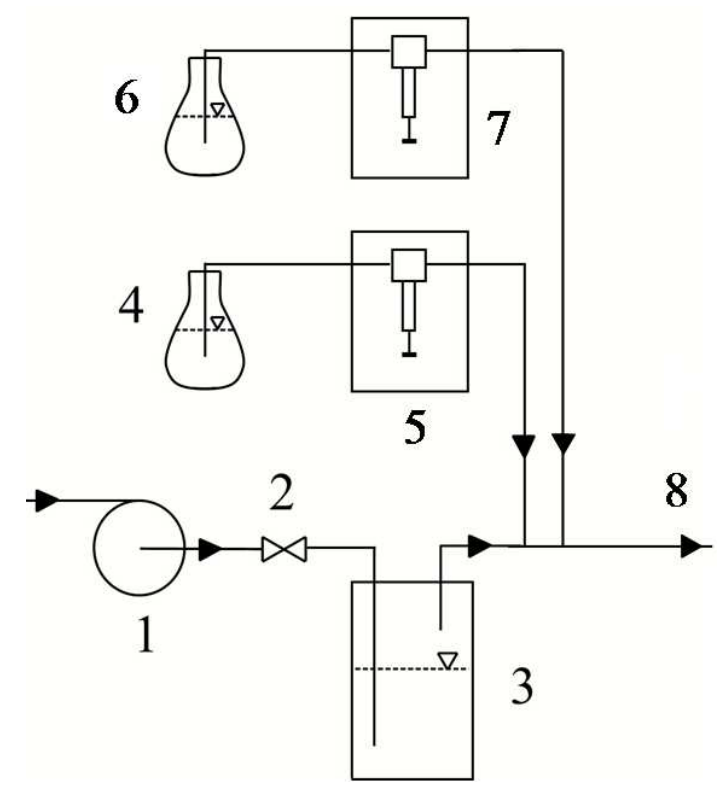

Figure 2 - Schematic showing production of artificially polluted air 1 - blower, 2 - needle valves for flow rate control, 3 - humidification vessel, 4 - vessel with styrene, 5 - syringe pump, 6 - vessel with acetone, 7 - syringe pump, 8 - air inlet into the reactor. 


\section{Inoculum and culture medium}

The mixed microbial culture for inoculation was collected from a previously running styrenedegrading biofilter. An inoculum preparation was performed in 250-mL Erlenmeyer flasks containing $100 \mathrm{~mL}$ of mineral medium at 27-30 ${ }^{\circ} \mathrm{C}$ on a rotary shaker. After $96 \mathrm{~h}$ of fed batch cultivation, the cells were harvested, centrifuged and then re-suspended in fresh nutrient medium for use as an inoculum in the biodegradation experiments. The cultivation and degradation media had the following composition: $(\mathrm{g} / \mathrm{L})$ $\left(\mathrm{NH}_{4}\right)_{2} \mathrm{SO}_{4} \quad 2.00 ; \quad \mathrm{KNO}_{3} \quad 1.00 ; \mathrm{K}_{2} \mathrm{HPO}_{4} \quad 4.30$; $\mathrm{KH}_{2} \mathrm{PO}_{4}$ 3.40; $\mathrm{MgCl}_{2} \cdot 6 \mathrm{H}_{2} \mathrm{O}$ 0.34. Trace element feed composition $(\mu \mathrm{g} / \mathrm{L})$ was: $\mathrm{FeSO}_{4} .7 \mathrm{H}_{2} \mathrm{O} 0.16$; $\mathrm{ZnSO}_{4} .7 \quad \mathrm{H}_{2} \mathrm{O} \quad 0.30 ; \mathrm{MnSO}_{4} . \mathrm{H}_{2} \mathrm{O} 0.10 ; \mathrm{CuSO}_{4}$. $5 \mathrm{H}_{2} \mathrm{O}$ 0.10; $\mathrm{Na}_{2} \mathrm{MoO}_{4} .2 \mathrm{H}_{2} \mathrm{O}$ 0.10; $\mathrm{CaSO}_{4} .0 .5$ $\mathrm{H}_{2} \mathrm{O}$ 0.15; $\mathrm{CoSO}_{4} .7 \mathrm{H}_{2} \mathrm{O} 0.10 ; \mathrm{Na}_{2} \mathrm{~B}_{4} \mathrm{O}_{7} .10 \mathrm{H}_{2} \mathrm{O}$ 0.10 .

\section{Pollutant supply}

The styrene used in this study was a monomer species; $99 \%$ reagent purity grade, inhibited with $0.005 \%$ of 4-tert-butylcatechol (Sigma-Aldrich Chemie, Germany), acetone p.a. (Penta Ltd., Chrudim, Czech Republic). To generate an air stream contaminated with styrene and acetone vapors, the flow of compressed air was forced through a glass T-pipe where a pollutant injection point was situated. A syringe pump (Gilson, France) ensured a continuous feed of styrene and acetone.

\section{Analytical methods}

Acetone and styrene in the influent and effluent gas were determined by GC analysis. Gaseous samples were taken manually and collected from each of the sampling ports using $500-\mu \mathrm{L}$ gas-tight syringes (Hamilton, USA). The gas chromatograph (Hewlett Packard 6890 Series, California, USA) was equipped with a flame ionization detector (FID). A 30 m HP INNOWAX crosslinked polyethyleneglycol capillary column $(0.53 \mathrm{~mm}$ i.d.; $1 \mu \mathrm{m}$ film thickness) was used for the experiment. GC analytical conditions were as follows: injection and detection temperatures 250 and 300 ${ }^{\circ} \mathrm{C}$, respectively, oven temperature $150{ }^{\circ} \mathrm{C}$, flow of argon as a carrier gas $6.3 \mathrm{~mL} / \mathrm{min}$. Under these conditions, the retention times of acetone and styrene were 1.1 and $1.9 \mathrm{~min}$, respectively.

\section{Theory Steady state data modeling}

For the steady state experiments, the well established Ottengraf models (as summarised in Devinny et al., 1999) were used. Ottengraf assumed that kinetics can be first-order, or zeroorder with reaction rate limitation, or zero-order with diffusion rate limitation. This model is simple and gives reasonable predictions of steady state behavior. Namkoong et al. (2004) successfully used similar first order models to describe the biofiltration results for gasoline compound removal in a soil vapour extraction application.

The model assumes that in plug flow, gas phase interfacial resistance is negligible, that the pollutant transport through the biofilm is caused by the diffusion, and that the biofilm thickness is small compared to the support particle diameter. The mathematical representations of the predicted concentration profiles for these three models (Ottengraf 1986; Ottengraf 1987) are as follows:

For first-order kinetics

$$
\frac{C_{g}}{C_{g i}}=\exp \left(-\frac{h K_{1}}{m v_{a}}\right)
$$

Later we will use:

$$
K_{1}^{\prime}=\frac{K_{1}}{m}
$$

For zero-order kinetics with reaction limitation

$$
\begin{aligned}
& \frac{C_{g}}{C_{g i}}=1-\left(\frac{h K_{0}}{C_{g i} v_{a}}\right) \\
& \frac{C_{g}}{C_{g i}}=\left[1-\frac{h}{v_{a}} \sqrt{\frac{K_{0} D_{e f f} a}{2 m C_{g i} \delta}}\right]^{2}
\end{aligned}
$$

and combining the constants:

$$
K_{0}{ }^{\prime}=\sqrt{\frac{K_{0} \cdot D_{\text {eff }} \cdot a}{2 m \delta}}
$$


rom these equations, it could be concluded that the concentration profile along the height of the biofilter could be linear, quadratic or exponential. Hence, the concentration ratio, its square root and its natural logarithm $\left[\left(\mathrm{C}_{\mathrm{g}} / \mathrm{C}_{\mathrm{gi}}\right), \quad \sqrt{ }\left(\mathrm{C}_{\mathrm{g}} / \mathrm{C}_{\mathrm{gi}}\right)\right.$, $\left.\ln \left(\mathrm{C}_{\mathrm{g}} / \mathrm{C}_{\mathrm{gi}}\right)\right]$ were plotted against the bed height, $h$. Trend lines were added to these graphs and the $R^{2}$ values were calculated. Using the equations mentioned before, the values of kinetic constants $\left(K_{0}, K_{0}{ }^{\prime}, K_{l}{ }^{\prime}\right)$ were calculated. To demonstrate the consistency of these kinetic parameters, the coefficient of variation (defined by: standard deviation/mean) was calculated. At this point, a final decision about the selection of the most suitable model could be made by choosing the optimal values of $R^{2}$ and the coefficient of variation.

\section{Unsteady state data modeling}

There are a number of detailed models of unsteady state biofilters (Lu et al., 2004, Chmiela et al., 2005). In order to use as simple an approach as possible to represent the experimental data, the software package Control Station (Cooper, 2003) was used with a first order with dead-time model. The values of time constant, dead time and gain were used to fit the dynamic data. The first order plus dead-time model proved to be a simple and adequate representation of the system. Often, the dead times were small or zero, so the simplest representation of the dynamics could be:

$$
-\frac{d c}{d t}=k\left(c-c_{n e w}\right)
$$

hence,

$$
\int_{c_{0}}^{c} \frac{d c}{\left(c-c_{\text {new }}\right)}=-k \int_{0}^{t} d t
$$

or,

$$
\ln \left(\frac{c-c_{\text {new }}}{c_{0}-c_{\text {new }}}\right)=-k t
$$

Finally,

$$
c=c_{\text {new }}+\left(c_{0}-c_{\text {new }}\right) \exp (-k t)
$$

Of course,

$$
k=\frac{1}{\tau}
$$

With boundary conditions:

$$
\text { At } \quad \begin{array}{ll}
\mathrm{t}=0 & \mathrm{c}=\mathrm{c}_{0} \\
\mathrm{t} \rightarrow \infty & \mathrm{c}=\mathrm{c}_{\text {new }}
\end{array}
$$

This approach was used to clarify what was occurring in the transient conditions of the acetone and styrene experiments. The transient interactions between another pair of hydrophilic and hydrophobic compounds (methanol and $\alpha$-pinene) in a trickling filter have been reported (Mohseni and Grant Allen 1999).

\section{Experimental strategy}

Steady state conditions

i. Experiment (i) with Pall rings $(25 \times 25 \times 1$ $\mathrm{mm}$ ) and changes in air flow rate

The steady state styrene concentrations were measured at the inlet, intermediate and exit positions of the bed. The inlet concentration of the styrene was kept constant during the experiment. The airflow rate was increased gradually from 20 to $80 \mathrm{~L} / \mathrm{min}$. Data were divided into seven groups according to the gas flow rate $(20,30,40 \ldots 80$ $\mathrm{L} / \mathrm{min}$ ) and these data were investigated using the Ottengraf model theory mentioned previously.

ii. Experiment (ii) with small Pall rings $(15 \times 15 \times 1 \mathrm{~mm})$ with changes in the inlet concentration of styrene, with some acetone present.

The inlet concentration of styrene was steadily increased and the air flow rate $(20 \mathrm{~L} / \mathrm{min})$ and concentration of acetone $\left(50 \mathrm{mg} / \mathrm{m}^{3}\right)$ were both kept constant. The data were divided into seven groups according to the inlet concentration of styrene $\left(0-100 \mathrm{mg} / \mathrm{m}^{3}, 100-200 \mathrm{mg} / \mathrm{m}^{3} \ldots\right.$ up to $\left.600-700 \mathrm{mg} / \mathrm{m}^{3}\right)$. The data obtained were investigated and used for the development of the most suitable steady state model.

\section{Unsteady state conditions}

The unsteady state data (experiment iii) were obtained as a response to changes of the inlet concentration of both styrene and acetone with the air flow-rate held constant. Three main concentration shifts were made. At first, the inlet concentration of styrene was decreased from 580 to $500 \mathrm{mg} / \mathrm{m}^{3}$, and simultaneously the inlet 
concentration of acetone was decreased from 280 to $0 \mathrm{mg} / \mathrm{m}^{3}$. The second change was a styrene inlet concentration drop from 500 to $50 \mathrm{mg} / \mathrm{m}^{3}$ with the acetone concentration remaining at $0 \mathrm{mg} / \mathrm{m}^{3}$. The third step change increased the inlet concentration of styrene from 50 back to the original level of 580 $\mathrm{mg} / \mathrm{m}^{3}$ with the acetone changing from 0 to 280 $\mathrm{mg} / \mathrm{m}^{3}$. The lengths of the step loading periods were 2, 6 and $16 \mathrm{~h}$ (only the inlet and outlet concentrations were measured during these unsteady state experiments.) Some typical unsteady state data are represented by Figure 3 (each experiment was repeated).

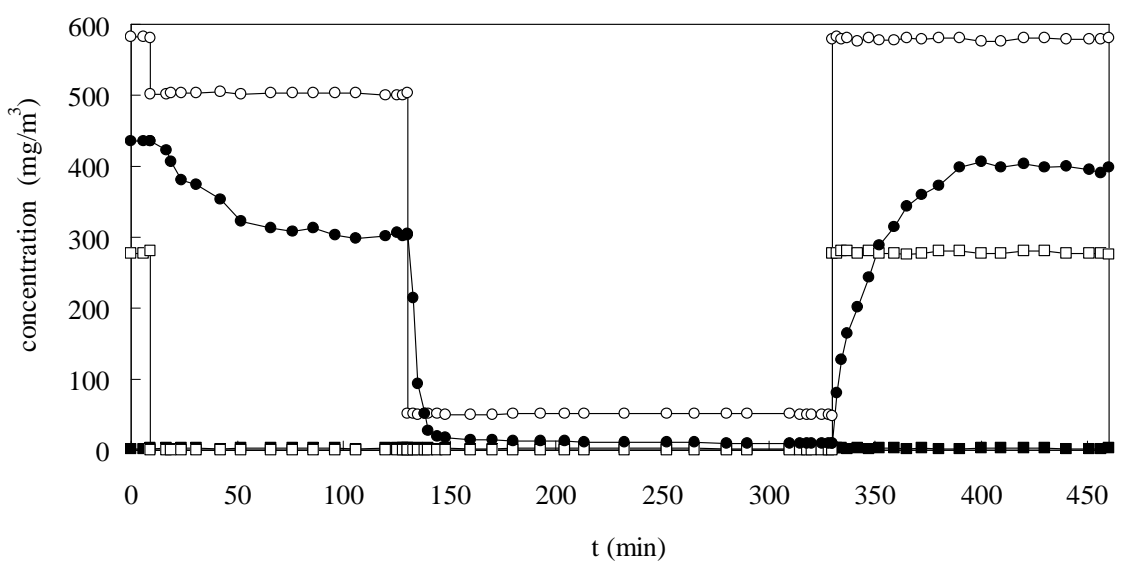

Figure 3 - Typical unsteady concentration profile for step changes in styrene and acetone feed levels at constant air flow-rate. (Third [iii] experiment). $\circ-\mathrm{C}_{\text {in (STY) }}, \bullet-\mathrm{C}_{\text {out (STY) }}, \mathbf{-}-$ $\mathrm{C}_{\text {out }(\mathrm{AC})}, \square-\mathrm{C}_{\text {out }(\mathrm{AC})}$.

\section{RESULTS AND DISCUSSION}

\section{Steady state}

Experiment i ----with larger Pall rings $(25 \times 25 \times 1$ $\mathrm{mm})$ and changes in air flow rate. Various steady state models were developed according to Ottengraf's model, equations (1)-(3). Both from the appearance of the concentration profiles and from the value of the coefficient of determination, $R^{2}$, (Table 1), the zero order diffusional model seemed reasonable but it was difficult to be absolutely sure, so a second measure was used. In this case the consistency of the value of the determined kinetic parameters $\left(K_{0}, K_{0}^{\prime}\right.$, and $\left.K_{l}^{\prime}\right)$ as measured by the coefficient of variation was looked (Table 2). This test confirmed that the diffusion limited, zero order model was the best for this application because the variation of the experimental constant was smallest (in the tables, the best cases are shown in bold type). However, it was interesting to note that other work (Kim et al., 2005), which studied styrene removal in a more complex mixture, favoured a first order model with a rate constant of $0.044 \mathrm{~s}^{-1}$ compared to the $0.04 \mathrm{~s}^{-1}$ averaged figure reported (Table 2).

Table 1 - Average $R^{2}$ values of trend lines for the experiment with larger Pall ring $(25 \times 25 \times 1 \mathrm{~mm})$. The best fits for each flow rate are highlighted in bold. Styrene removal only, under steady state conditions.

\begin{tabular}{llll}
\hline \multicolumn{2}{l}{ Average $\mathbf{R}^{2}$ values } & for the three models & \\
\hline Air flow rate (L/min) & Zero order, reaction limitation & Zero order, diffusion limitation & First order \\
\hline 20 & 0.9509 & 0.9877 & $\mathbf{0 . 9 8 8 0}$ \\
\hline 30 & 0.9613 & $\mathbf{0 . 9 9 6 1}$ & 0.9815 \\
\hline 40 & 0.9954 & $\mathbf{0 . 9 9 8 5}$ & 0.9859 \\
\hline 50 & 0.9936 & $\mathbf{0 . 9 9 7 5}$ & 0.9946 \\
\hline 60 & $\mathbf{0 . 9 9 8 9}$ & 0.9972 & 0.9917 \\
\hline 70 & 0.9910 & 0.9951 & $\mathbf{0 . 9 9 8 9}$ \\
\hline 80 & 0.9990 & $\mathbf{0 . 9 9 9 4}$ & 0.9975 \\
\hline
\end{tabular}


Table 2 - Average values of kinetic parameters $K_{0}, K_{0}^{\prime}$, and $K_{l}^{\prime}$, mean, standard deviation and coefficient of variation $\left(c_{v}\right)$ for Pall rings $(25 \times 25 \times 1 \mathrm{~mm})$. Styrene removal only, under steady state conditions.

\begin{tabular}{|c|c|c|c|}
\hline Average $\mathrm{K}$ values & for the three models & & \\
\hline $\begin{array}{l}\text { Air flow rate } \\
\text { (L/min) }\end{array}$ & $\begin{array}{l}\mathrm{K}_{0^{-}} \text {zero order reaction } \\
\text { limitation }\left(\mathrm{mg} / \mathrm{m}^{3} / \mathrm{s}\right)\end{array}$ & $\begin{array}{l}\mathrm{K}_{0}{ }^{\prime}-\text { zero order diffusion } \\
\text { limitation }\left(\mathrm{mg}^{0.5} / \mathrm{m}^{1.5} / \mathrm{s}\right)\end{array}$ & $\begin{array}{l}K_{1}^{\prime} \text { - first order } \\
\left(\mathrm{s}^{-1}\right)\end{array}$ \\
\hline 20 & 1.70 & 0.12 & 0.04 \\
\hline 30 & 2.69 & 0.19 & 0.06 \\
\hline 40 & 2.73 & 0.17 & 0.04 \\
\hline 50 & 2.98 & 0.17 & 0.04 \\
\hline 60 & 2.59 & 0.14 & 0.03 \\
\hline 70 & 2.71 & 0.15 & 0.03 \\
\hline 80 & 2.88 & 0.15 & 0.03 \\
\hline \multicolumn{4}{|c|}{ Mean, standard deviation and coefficient of variation $\left(\mathrm{c}_{\mathrm{v}}\right)$} \\
\hline Mean & 2.61 & 0.16 & 0.04 \\
\hline Standard deviation & 0.42 & 0.02 & 0.01 \\
\hline $\begin{array}{l}\text { Coefficient of } \\
\text { variation }\left(c_{v}\right)\end{array}$ & 0.16 & 0.15 & 0.28 \\
\hline
\end{tabular}

Experiment ii---with Pall rings $(15 \times 15 \times 1 \mathrm{~mm})$ and changes in the inlet concentration of styrene while keeping the inlet acetone concentration constant (at $50 \mathrm{mg} / \mathrm{m}^{3}$ ).

Ottengraf's models were also used for the second set of data. Table 3 showed that the values of $R^{2}$ were consistent and similar. However, with these values of coefficients of determination $\left(R^{2}\right)$, it was again not sure which model offered the best fit. Hence, the coefficients of variation $\left(c_{v}\right)$, of kinetic parameters $\left(K_{0}, K_{0}^{\prime}, K_{l}^{\prime}\right)$ were used to make a final decision about the suitability of the model. According to the coefficient of variation, again the best choice was zero order kinetics with diffusion limitation model (Table 4) for the steady state conditions of the biofilter operation. Raqhuvanshi and Babu (2009) confirmed a suitability of this model during methyl ethyl ketone biofiltration.

\section{Unsteady state model}

Figure 3 shows some typical dynamic data. Five experiments were completed involving three step changes (Table 5). The results from using the Control Station package led to the fitting of this experimental data to a "first order plus dead time model". The time constant, dead time and gain were fitted to the data. A typical graph with results from Control Station is given in Figure 4, and the numerical results are summarized in Table 6. This showed only the dynamic response of the changes in the styrene concentrations, because the acetone exit concentration responded almost instantaneously to the change in the feed concentrations. Others have shown that the acetone was easy to remove in a trickle bed (Pielech-Przybylska et al., 2006).

Table 3 - Average $\mathrm{R}^{2}$ values of trend lines for the experiment with Pall rings $(15 \times 15 \times 1 \mathrm{~mm})$ under steady state conditions.

\begin{tabular}{llll}
\hline $\begin{array}{l}\text { Average } \mathbf{R}^{\mathbf{2}} \text { values } \\
\text { Range of concentration } \\
\left(\mathbf{m g} / \mathbf{m}^{\mathbf{3}}\right)\end{array}$ & Zero order reaction limitation & Zero order diffusion limitation & First order \\
\hline $0-100$ & 0.8346 & 0.9556 & $\mathbf{0 . 9 7 9 9}$ \\
\hline $100-200$ & 0.9015 & 0.9699 & $\mathbf{0 . 9 7 3 3}$ \\
\hline $200-300$ & 0.9407 & $\mathbf{0 . 9 7 8 9}$ & 0.9776 \\
\hline $300-400$ & 0.9785 & $\mathbf{0 . 9 9 3 2}$ & 0.9921 \\
\hline $400-500$ & 0.8778 & 0.9000 & $\mathbf{0 . 9 1 8 6}$ \\
\hline $500-600$ & 0.9727 & 0.9828 & $\mathbf{0 . 9 8 5 3}$ \\
\hline $600-700$ & $\mathbf{0 . 9 8 7 1}$ & 0.9867 & 0.9867 \\
\hline
\end{tabular}


Table 4 - Average values of kinetic parameters $K_{0}, K_{0}^{\prime}$, and $K^{\prime}$, mean, standard deviation and coefficient of variation $\left(\mathrm{c}_{\mathrm{v}}\right)$ for Pall rings $(15 \times 15 \times 1 \mathrm{~mm})$ under steady state conditions.

\begin{tabular}{|c|c|c|c|}
\hline \multicolumn{4}{|c|}{ Average $K$ values for the three models (using a mixture of styrene and acetone) } \\
\hline $\begin{array}{c}\text { Range of concentration } \\
\left(\mathbf{m g} / \mathrm{m}^{\mathbf{3}}\right)\end{array}$ & $\begin{array}{c}\mathbf{K}_{0^{-}} \text {zero order } \\
\text { reaction limitation } \\
\left(\mathrm{mg} / \mathrm{m}^{3} / \mathrm{s}\right)\end{array}$ & $\begin{array}{c}\mathbf{K}_{0}{ }^{\prime}-\text { zero order } \\
\text { diffusion limitation } \\
\left(\mathrm{mg}^{0.5} / \mathrm{m}^{1.5} / \mathrm{s}\right)\end{array}$ & $\begin{array}{c}K_{1}^{\prime}-\text { first order } \\
\left(s^{-1}\right)\end{array}$ \\
\hline $0-100$ & 1.26 & 0.14 & 0.08 \\
\hline $100-200$ & 6.11 & 0.20 & 0.06 \\
\hline $200-300$ & 4.00 & 0.18 & 0.04 \\
\hline $300-400$ & 4.50 & 0.15 & 0.02 \\
\hline $400-500$ & 5.29 & 0.15 & 0.02 \\
\hline $500-600$ & 5.89 & 0.15 & 0.02 \\
\hline $600-700$ & 1.40 & 0.03 & 0.002 \\
\hline \multicolumn{4}{|c|}{ Mean, standard deviation and coefficient of variation $\left(\mathrm{c}_{\mathrm{v}}\right)$} \\
\hline Mean & 4.06 & 0.14 & 0.03 \\
\hline Standard deviation & 2.00 & 0.05 & 0.03 \\
\hline Coefficient of variation $\left(\mathrm{c}_{\mathrm{v}}\right)$ & 0.49 & $\mathbf{0 . 3 8}$ & 0.79 \\
\hline
\end{tabular}

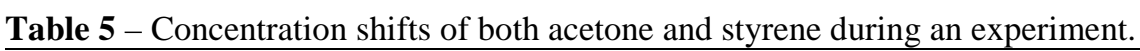

\begin{tabular}{|c|c|c|}
\hline Concentration changes & styrene $\left(\mathrm{mg} / \mathrm{m}^{3}\right)$ & acetone $\left(\mathrm{mg} / \mathrm{m}^{3}\right)$ \\
\hline Step change $\mathrm{A}$ & $580 \rightarrow 500$ & $280 \rightarrow 0$ \\
\hline $\mathrm{B}$ & $50 \rightarrow 580$ & $0 \rightarrow 280$ \\
\hline $\mathrm{C}$ & $500 \rightarrow 50$ & 0 \\
\hline
\end{tabular}

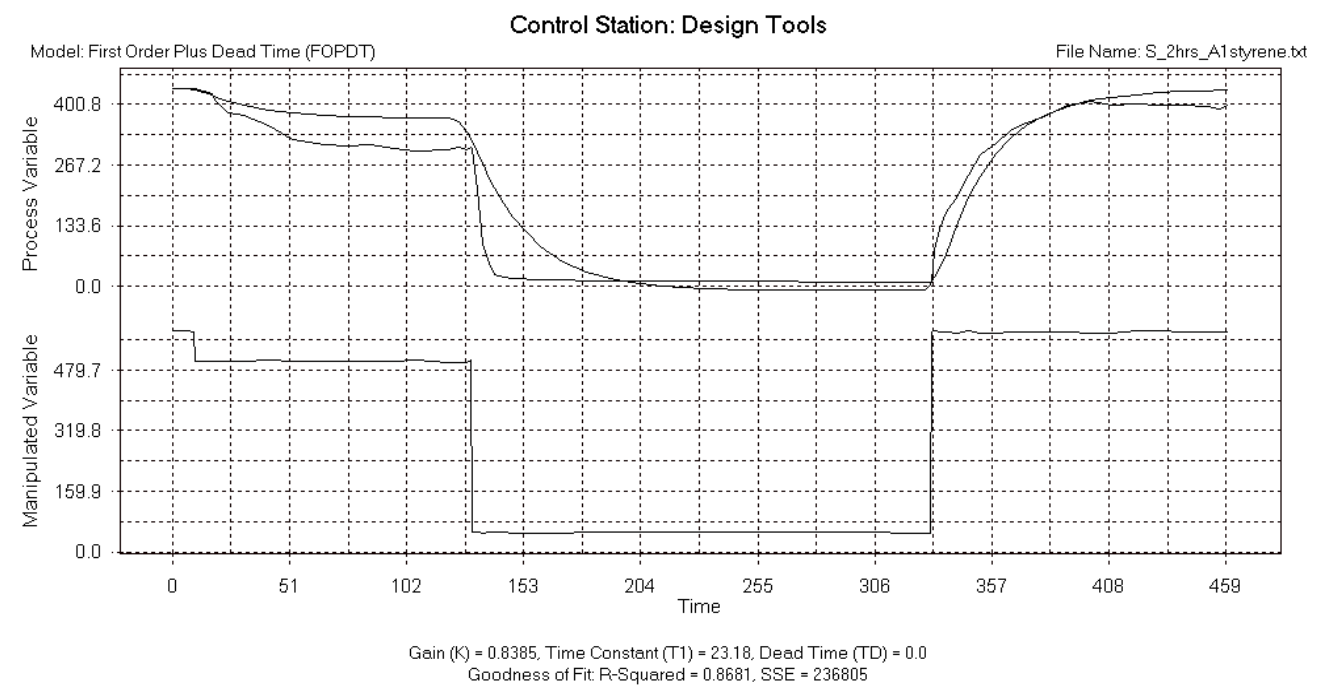

Figure 4 - First order plus dead time model fit and the experimental results for unsteady state styrene removal and a loading period of 2 hours.

Table 6 - Values of gain K, time constant $\tau$ and dead time $\tau_{\mathrm{d}}$ obtained from Control Station.

\begin{tabular}{ccccc}
\hline experiment number & gain $(\mathbf{K})$ & Time-constant, $\boldsymbol{\tau}(\mathbf{m i n})$ & Dead-time, $\boldsymbol{\tau}_{\mathbf{d}}(\mathbf{m i n})$ & $\mathbf{R}^{\mathbf{2}}$ \\
\hline 1 & 0.8385 & 23.18 & 0 & 0.8681 \\
\hline 2 & 0.8293 & 10.3 & 0 & 0.8615 \\
\hline 3 & 0.9719 & 41 & 0 & 0.6868 \\
\hline 4 & 0.8437 & 12.91 & 0 & 0.9204 \\
\hline 5 & 0.9252 & 11.59 & 0 & 0.95 \\
\hline
\end{tabular}


Because the Control Station results had shown the lack of any significant dead-time (Table 6), a second, simpler approach was adopted to the unsteady state modelling, using equation (6). Hence, the natural logarithm of concentration ratio, $\ln \left(\left(c-c_{\text {new }}\right) /\left(c_{0}-c_{\text {new }}\right)\right)$ was plotted against time and the values of constant $k$ were easily obtained as a slope of this linear relationship. The coefficients of determination $\left(R^{2}\right)$ were also tabulated to show the goodness of fit (Table 7). This table showed that the values of the dynamic parameter, $\mathrm{k}$, were much larger in the row corresponding to step change $\mathrm{C}$.

Table 7 - Values of slopes of trend lines $(k)$ and coefficients of determination $R^{2}$ in the absorption model.

\begin{tabular}{|c|c|c|c|c|c|}
\hline \multicolumn{6}{|c|}{ Values of slopes of trend lines $k$ in the unsteady state model } \\
\hline \multirow{2}{*}{$\begin{array}{l}\text { Change in } \\
\text { concentration }\end{array}$} & \multicolumn{5}{|c|}{ Experiment } \\
\hline & 1 & 2 & 3 & 4 & 5 \\
\hline$A$ & -0.0452 & -0.0832 & -0.0454 & -0.0500 & -0.0804 \\
\hline$B$ & -0.0552 & -0.0866 & -0.0552 & -0.0669 & -0.052 \\
\hline$C$ & -0.2669 & -0.1911 & -0.2045 & -0.2641 & -0.2013 \\
\hline \multicolumn{6}{|c|}{ Coefficients of determination $R^{2}$ in the unsteady state model } \\
\hline$A$ & 0.8666 & 0.8761 & 0.9594 & 0.9945 & 0.9638 \\
\hline$B$ & 0.9946 & 0.9795 & 0.9871 & 0.9803 & 0.9799 \\
\hline$C$ & 0.9793 & 0.7663 & 0.9101 & 0.9965 & 0.9856 \\
\hline
\end{tabular}

When there was a small decrease in styrene and the acetone (i.e. step change A, Table 5), there was a relatively slow change, and hence, $\mathrm{k}$ was small, as the acetone was very soluble and there was a small residual amount in the liquid, the microorganisms could consume it for a short time after the acetone supply was shut down. This slow response also occured for the second concentration step change, B. In this case, the microorganisms started preferentially to quickly degrade the more easily assimilated acetone and the styrene degradation followed after a lag-time. It is also necessary to take into account that the transport rate of the hydrophilic acetone to the active sites of the intracellular enzymes is faster than that of styrene. The fastest response occured (with the higher $\mathrm{k}$ value) when there was no acetone present at all (step change C), so the only substrate present was styrene and there is no choice but for it be consumed, after a very short period of transport to the cells.

\section{CONCLUSIONS}

\section{Steady state models.}

The zero - order kinetic model with diffusion limitation was the most suitable model for describing both sets of steady state data (with large
Pall rings $(25 \times 25 \times 1 \mathrm{~mm})$ and small Pall rings $(15 \times 15 \times 1 \mathrm{~mm}))$. The model selection was made by choosing the best average values of $R^{2}$ and the coefficient of variation. Overall, a value of $K_{0}^{\prime}=0.15\left(\mathrm{mg}^{0.5} / \mathrm{m}^{2} / \mathrm{s}\right)$ represented both sets of experiments. Hence, the overall effect of the small amount of acetone present in the second experiment and the change in the size of the packings appeared to have little effect on the kinetics of the removal of styrene.

\section{Unsteady state model.}

Equations 6 or 7 were a particularly simple representation of the overall process dynamics for the removal of styrene in the presence of acetone. There was evidence that the microorganisms prefer to consume the more easily digested acetone. In the presence of both components, the adaptation to a step change in styrene concentration was slower than when only styrene was present, as explained above.

\section{ACKNOWLEDGEMENT}

The work was financially supported by the projects MSM 6046137305 and AMVIS ME09031 both supplied by the Ministry of Education of the Czech Republic. 


\section{NOMENCLATURE}

$a$ - ratio of surface to volume, $\mathrm{m}^{-1}$

$c$ - actual outlet concentration of pollutant, $\mathrm{g} / \mathrm{m}^{3}$

$c_{0}$-initial outlet concentration of pollutant, $\mathrm{g} / \mathrm{m}^{3}$

$c_{\text {new }}$ - new outlet concentration of pollutant at the

new steady state, $\mathrm{g} / \mathrm{m}^{3}$

$C_{g}$ - gas concentration, $\mathrm{g} / \mathrm{m}^{3}$

$C_{g i}$ - inlet gas concentration, $\mathrm{g} / \mathrm{m}^{3}$

$C_{i n}$ - inlet concentration, $\mathrm{g} / \mathrm{m}^{3}$

$C_{\text {out }}$ - outlet concentration, $\mathrm{g} / \mathrm{m}^{3}$

$D_{\text {eff }}-$ effective diffusion coefficient, $\mathrm{m}^{2} / \mathrm{s}$

$h$ - filter bed height, $\mathrm{m}$

$k$ - parameter in simple dynamic model, $\min ^{-1}$

$K$ - gain

$K_{0}-$ zero order reaction constant (reaction limitation)

$K_{l}$ - first order reaction rate constant

$K_{0}^{\prime}-$ combined zero order reaction constant (diffusion limitation)

$K_{l}^{\prime}-$ combined first order reaction rate constant

$m$ - gas equilibrium constant

$t$ - time, $\mathrm{s}$

$v_{a}-$ superficial velocity, $\mathrm{m} / \mathrm{s}$

$\delta$ - biolayer thickness, $\mathrm{m}$

$\tau$ - time constant, $\min$

$\tau_{d}-$ dead time (min)

subscripts

AC - acetone

STY - styrene

\section{REFERENCES}

Baltzis, B.C., Wojdyla, S.M., and Zarook, S.M. (1997), Modelling of VOC mixtures under a steady state conditions. J Environ Eng-ASCE, 6, 599-605.

Choi, D., Devinny, J.S . and Deshusses, M.A. (2004),

Behavior of Field-Scale Biotrickling Filter under NonsteadyState Conditions. J Environ Eng, 322-328.

Chmiela, K., Koniecznya, A., Palica, M., Jarzebskia, A.B. (2005), Periodic operation of biofilters. A concise model andexperimental validation. Chem Eng Sci, 60, 2845-2850.

Cooper, D.J. (2003), Control Station package, University of Connecticut, USA.

Devinny, J.S. , Deshusses, M.A. , Webster, T.S. (1999), Biofiltration for air pollution control, Lewis Publishers, CRC Press, pp. 113-120.
Gerrard, A.M., Hajkova, D., Halecky, M. and Paca, J. (2002), Steady state and transient models for the biofiltration of styrene/air mixtures. Proceedings of 15th International Congress of Chemical and Process Engineering, session K2, paper no 52, pp. 25-29 August, Prague, Czech Republic.

Kennes, C., Thalasso, F. (1998), Waste Gas Biotreatment Technology. J Chem Technol Biotechnol, 72, 303-319.

Kim, D., Cai, Z. and Sorial, G.A. (2005), Impact of interchanging VOCs on the performance of trickle bed air biofilter. Chem Eng J, 113, 153-160.

Lu, C., Chang, K ., and Hsu, S. (2004), A model for treating isopropyl alcohol and acetone mixtures in a trickle-bed air biofilter. Process Biochem, 39, 18491858.

Mohseni, M., and Grant Allen, D. (1999), Transient Performance of Biofilters Treating Mixtures of Hydrophilic and Hydrophobic Volatile Organic Compounds. J Air and Waste Manage Assoc, 49, 1434-1441.

Ottengraf, S. P. P. (1986), Biofilters in Biotechnology, VCH, Verlagsgeselltschaft, Weinheim, pp. 436-446.

Namkoong, W., Park, J., VanderGheynst, J. (2004), Effect of gas velocity and influent concentration on biofiltration of gasoline off-gas from soil vapor extraction, Chemosphere, 57, 721-730.

Ottengraf, S. P. P. (1987), Biological systems for waste gas elimination. Trends Biotechnol, 5, 132-136.

Paca, J., Klapkova, E., Halecky, M., Jones, K., Soccol, C.R. (2007), Performance evaluation of a biotrickling filter degrading mixtures of hydrophobic and hydrophilic compounds. J Clean Techn Environ Policy, 9, 69-74.

Pielech-Przybylska, K, Zieminski, K., and Szopa, J.St. (2006), Acetone biodegradation in a trickle-bed biofilter. Int Biodeter Biodegr, 57, 200-206.

Raghuvanshi, S., Babu, B.V. (2009), Experimental studies and kinetic modelling for removal of methyl ethyl ketone using biofiltration. Bioresource Technol, 100, 3855-3865.

Sorial, G. A., Smith, F. L., Suidan, M. T., Pandit, A., Biswas, P., and Brenner, R., C. (1998), Evaluation of trickle-bed air biofilter performance for styrene removal. Wat Res, 32, 1593-1603.

Wright, W. F. (2005), Transient response of vaporphase biofilters. Chem Eng J, 113, 161-173.

Raghuvanshia S Babu B.V. (2009), Experimental studies and kinetic modeling for removal of methyl ethyl ketone using biofiltration. Bioresource Technol, 100, 3855-3861. 